\title{
IDOSOS RIBEIRINHOS DA AMAZÔNIA BRASILEIRA NO ENFRENTAMENTO DA COVID-19
}

\author{
Fernanda Farias de Castro' \\ ORCID: 0000-0003-1970-5169
}

Cássia Rozária da Silva Souza'

ORCID: 0000-0001-9790-3713

Cleisiane Xavier Diniz'

ORCID: 0000-0003-4689-6204

Elen Petean Parmejiani"

ORCID: 0000-0002-0512-8172

Fabíola Silva Santos' ORCID: 0000-0002-3207-2987

Josiani Nunes do Nascimento"'I ORCID: 0000-0001-6841-9551

Maria de Nazaré de Souza Ribeiro' ORCID: 0000-0002-7641-1004

Pedro Augusto Paula do Carmo'v ORCID: 0000-0001-6269-5264

Valéria Moreira da Silva" ORCID: 0000-0001-6786-6325

Vanusa do Nascimento $v$ ORCID: 0000-0003-4141-2784

'Universidade do Estado do Amazonas, Escola Superior de Ciências da Saúde. Manaus, Amazonas, Brasil.

" Fundação Universidade Federal de Rondônia. Porto Velho, Rondônia, Brasil.

II' Secretaria de Saúde do Estado do Amazonas-SUSAM, Hops. e PS João Lúcio. Manaus, Amazonas, Brasil.

Iv Secretaria Municipal de Saúde de Porto Velho. Porto Velho, Rondônia, Brasil.

VFundação Universidade Aberta da Terceira Idade - FUnATI. Manaus, Amazonas, Brasil.

Autor Correspondente:

Fernanda Farias de Castro E-mail: fcastro_uea@hotmail.com

Como citar:

Castro FF, Souza CRS, Diniz CX, Parmejiani EP, Santos FS, Nascimento JN, et al. Idosos ribeirinhos da Amazônia Brasileira no enfrentamento da covid-19. In: Santana RF (Org.). Enfermagem gerontologica no cuidado do idoso em tempos da COVID 19. 2.ed.rev. Brasilia, DF: Editora ABEn; 2020.

p 131-138. (Serie Enfermagem e Pandemias, 2). https://doi.org/10.51234/aben.20.e02.c20

\section{INTRODUÇÃO}

O vírus da família dos coronavírus responsável pela síndrome respiratória aguda grave, nomeado de SARS-CoV-2, causador da COVID-19, possui alta capacidade para infectar seres humanos e rápida disseminação geográfica, com quadro clínico variando de infecções respiratórias assintomáticas a quadros graves ${ }^{(1)}$. Dados do Ministério da Saúde revelaram que, em meados de junho de 2020, o Brasil ultrapassou um milhão de casos confirmados e mais de 50 mil mortes por COVID-19, entre os óbitos, $69,4 \%$ eram pessoas com mais de 60 anos e $63,0 \%$ delas possuíam ao menos um fator de risco.

Dentre as regiões de saúde brasileiras, as cinco que apresentaram maiores coeficientes de incidência estavam localizadas na região Norte do país, em área da Amazônia brasileira: Amazonas, abrangendo as regiões do Rio Negro e Solimões, Triângulo e Alto Solimões; as demais estavam no estado do Amapá, compreendendo a Área Sudoeste e Área Central. Com relação ao coeficiente de mortalidade, a região metropolitana I no Pará e quatro regiões de saúde no Amazonas (Manaus; Alto Rio Negro; Rio Negro e Solimões; Alto Solimões e Triângulo) ocuparam o segundo e terceiro lugar, respectivamente, só ficando atrás do estado do Ceará (região metropolitana de Fortaleza) ${ }^{(2)}$.

O avanço da COVID-19 no Brasil teve uma evolução rápida, atingindo as principais capitais dos estados, chegando a pequenas cidades e em áreas rurais, como as comunidades ribeirinhas da Amazônia brasileira. Banhada pela maior bacia hidrográfica do mundo, seu território é constituído por nove Estados e ocupam $61 \%$ do território do país, abrigando $12 \%$ da população que enfrentam diversos problemas sociais e econômicos. A Amazônia brasileira possui, ao longo de sua extensão, inúmeras comunidades ribeirinhas, com características étnicas de distintos grupos sociais (indígenas, nordestinos, negros e brancos) e tem como modo de vida principal a vivência às margens dos rios, do qual depende o atendimento às necessidades básicas e as mais variadas formas de subsistência. O termo 
ribeirinho designa os indivíduos que possuem uma estreita relação com os rios, ou seja, andam e vivem às margens dos rios ou ribeiras, e dele dependem para o sustento, relações sociais, locomoção, comunicação e sobrevivência ${ }^{(3-6)}$.

Considerando o avanço da pandemia para essas comunidades, a grande dispersão geográfica e a pouca cobertura do sistema de saúde, a Amazônia brasileira vivencia um dos momentos mais críticos da história da saúde pública: conter, tratar e atenuar o número de indivíduos contaminados pela COVID-19, e evitar que evoluam para estados de gravidade, necessitando de hospitalização, principalmente os idosos e adultos com Doenças Crônicas Não-Transmissíveis (DCNTs) prévias (hipertensão, obesidade, diabetes mellitus, doenças cardiovasculares) que possuem maior risco de gravidade e morte pela doença.

Este desafio torna-se maior nessa região que enfrenta um crescimento populacional em franca expansão; que convive com problemas de saúde já equacionados em outras partes do Brasil; que possui um vasto território ocupado por uma população dispersa com grande diversidade étnica, ocorrência de doenças negligenciadas, presença de malária, dengue, doenças diarreicas, entre outras. Soma-se a essa realidade, a complexidade de organização da assistência, que na sua forma atual, não atende às necessidades de serviços demandados pela população ribeirinha, em termos de condições de acesso, qualidade, integralidade e equidade.

Na região amazônica, utiliza-se uma dinâmica diferenciada na prestação de cuidados à saúde da população que vivem nas zonas rurais. Por meio da Estratégia Saúde da Família (ESF), recebem assistência em períodos previamente planejados, levando em consideração a cheia e vazante dos rios para o deslocamento das equipes. Os profissionais mais atuantes nessas localidades são o Enfermeiro e o Agente Comunitário de Saúde (ACS), que muitas vezes executam atividades limítrofes para atender os anseios da população e enfrentam inúmeras dificuldades de deslocamento, falta de insumos, medicamentos e apoio dos órgãos competentes. A escassez de estudos que abordem a temática de COVID-19 em populações que vivem em situação de vulnerabilidade, como os ribeirinhos, torna o assunto de alta relevância.

\section{OBJETIVO}

Refletir sobre as questões relacionadas à saúde dos idosos ribeirinhos da Amazônia brasileira e as ações realizadas para seu atendimento no enfrentamento da pandemia da COVID-19.

\section{MÉTODO}

Trata-se de estudo teórico-reflexivo sobre idosos ribeirinhos, tendo como cenário de (re)construção de ideias a Amazônia brasileira e as exigências de cuidados gerontológicos para esse segmento populacional no enfrentamento da pandemia por COVID-19.

As reflexões deste estudo teórico-reflexivo foram embasadas em artigos científicos relacionados ao tema, documentos oficiais do Ministério da Saúde, da Associação Brasileira de Enfermagem, da Sociedade Brasileira de Geriatria e Gerontologia, e da vivência e experiência das autoras. O texto propõe discussão e reflete sobre as peculiaridades dos idosos ribeirinhos, espaço geográfico, condições socioeconômicas e de saúde, vivência, e cuidados gerontológicos para esse segmento populacional no enfrentamento da pandemia por COVID-19.

\section{RESULTADOS}

\section{CIRCUNSTÂNCIAS GEOGRÁFICAS, SOCIOECONÔMICAS E DE SAÚDE DE IDOSOS RIBEIRINHOS NA PANDEMIA DA COVID-19}

Das diversificadas formas que os espaços rurais assumem no território brasileiro, a menos conhecida talvez seja a da Amazônia, onde a vida respeita o tempo e os caminhos das águas. Na vastidão das matas e ao 
redor de rios, lagos, igarapés e igapós, essa floresta é habitada por indígenas, quilombolas e ribeirinhos, que compõem as principais populações tradicionais da Amazônia brasileira, sendo a maior delas, os ribeirinhos.

Descendentes da miscigenação de indígenas e colonizadores portugueses, os ribeirinhos, também conhecidos como caboclos, vivem às margens dos rios e com o biossistema da vegetação de várzea bastante fecundo. Esse ambiente é caracterizado por inundações sazonais, que divide o clima em uma estação seca e outra chuvosa ao longo do ano. Os ribeirinhos trabalham principalmente como pescadores, extrativistas vegetais e produtores de derivados da mandioca; vivem, na maioria das vezes, de forma isolada, plantam para consumo próprio (agricultura de subsistência) e vendem seu excedente nos mercados das cidades próximas. Suas relações sociais e de trabalho são regidas pela natureza e pela marcante influência da cultura indígena; os hábitos alimentares são limitados a consumos de peixe, farinha de mandioca, frutos da região e pequena variedade de leguminosas.

Geralmente, a família ribeirinha é numerosa, tendo como chefe da família o idoso, que mesmo com idade avançada, ainda pesca, lida com a roça e participa diretamente das atividades comunitárias. Os ribeirinhos são detentores de um amplo conhecimento sobre o cultivo e uso de plantas medicinais, ensinado de geração em geração pelos idosos da comunidade, que muitas das vezes se apresenta como a única alternativa de tratamento contra doenças ${ }^{(6)}$.

A longa distância que separa fisicamente as casas, não dificulta a relação de vizinhança e compadrio; o terreno alagado nos períodos de enchentes com construções de marombas para a criação e proteção dos animais e as pontes instáveis construídas entre a casa e a margem do rio, não impedem o trabalho e os afazeres dos habitantes da floresta. Em muitas dessas localidades, as condições de infraestrutura são precárias, a energia elétrica é inconstante, a população consome água diretamente do rio sem nenhum tipo de tratamento; a assistência à saúde converge para o atendimento na zona urbana das cidades mais próximas, com ações pontuais dos profissionais de saúde nas localidades; e existe grande dificuldade de acesso às informações, uma vez que muitos não possuem energia elétrica regular, com um limitado acesso aos meios de comunicação (televisão, telefone, rádio, internet etc.).

A malha fluvial é o único meio de transporte e comunicação, por onde chegam os alimentos, medicamentos e a assistência à saúde. É também pelas vias fluviais que os trabalhadores ribeirinhos escoam aquilo que produzem, oriundos de atividades extrativistas, roçados de farinha e a pesca. O acesso à cidade é circunscrito pela distância, que pode superar a $500 \mathrm{~km}$, com deslocamento de vários dias até a sede municipal mais próxima e, ser realizado somente por via fluvial. No cenário dessa floresta de dimensões colossais, aliado a um clima tropical, doenças infecciosas endêmicas da região cursam com gravidade, obrigando a população a esse tipo de deslocamento para tratamento em cidades longínquas ${ }^{(4-6)}$.

No momento em que o mundo passou a enfrentar a pandemia por COVID-19, vários moradores de cidades golpeadas pela doença, como Belém (PA), Santarém (PA) e Manaus (AM), migraram para pequenas comunidades dos afluentes dos rios e foram acolhidos por ribeirinhos, na tentativa de se proteger da doença, porém, alguns já portavam o vírus de forma assintomática e se tornaram a fonte principal de infecção, principalmente para pessoas idosas e outras do grupo de risco. Quando a situação da pandemia se agravou e casos novos foram identificados em áreas rurais, várias comunidades passaram a proibir novas chegadas e o trânsito de barcos de não moradores foram suspensos. E, por determinação da Organização Mundial da Saúde (OMS) e do Ministério da Saúde (MS), foram adotadas medidas restritivas de alcance comunitário que incluíam locais públicos principalmente igrejas, escolas, áreas de convívio social da comunidade e embarcações.

Com o aumento do número de casos, sem hospitais, sem profissionais para atender a demanda das comunidades e sem Unidade de Terapia Intensiva (UTI) na maior parte das sedes municipais, foi necessário transferir pacientes para as cidades de maior porte, cujos hospitais já se encontravam sobrecarregados antes da pandemia da COVID-19. Sob essa ótica, o deslocamento de um idoso ribeirinho com problemas graves de saúde exige planejamento, gastos e meios de transporte viável de acordo com a localidade, seguido de uma realidade dura de peregrinação por um leito em cidades das zonas urbanas que, normalmente, já enfrentam problemas em sua capacidade de atendimento. 
Dados do Instituto Brasileiro de Geografia e Estatística (IBGE) ${ }^{(7)}$ demonstram que, no Brasil, a população que necessita de serviços de saúde percorre $72 \mathrm{~km}$ em média para realizar atendimento ou procedimentos de complexidade média e baixa, como consultas, exames clínicos e radiológicos, dentre outros atendimentos que não necessite de internação. Em Manaus, capital do Amazonas, foi a cidade que recebeu pacientes que atravessaram as maiores distâncias, chegando a alcançar uma média de $418 \mathrm{~km}$ para tais atendimentos ou procedimentos. Quanto à procura por tratamentos especializados de alta complexidade e custos elevados, o percurso feito pelo paciente chega em média a $155 \mathrm{~km}$. Os estados de Roraima e Amazonas, localizados na região norte do Brasil, apresentam as duas maiores médias de deslocamento para atendimentos de alta complexidade, com 471 e $462 \mathrm{~km}$, respectivamente.

Em muitas áreas densas de florestas, o deslocamento de pacientes graves só é possível por meio de ambulanchas (lanchas que executam atendimento nas margens dos rios), helicópteros e aviões de pequeno porte que se arriscam para executar pouso em pequenos espaços entre as árvores da floresta. Toda essa dinâmica de deslocamento, por ser bastante onerosa, não está disponível para todos os pacientes, estando na lista de prioridade as crianças, idosos e doentes em grau elevado de gravidade ${ }^{(7)}$.

Além disso, as limitações já existentes para os deslocamentos de pessoas ribeirinhas aos grandes centros urbanos e vice-versa, acrescidas da necessidade de distanciamento social durante a pandemia da COVID-19, impactaram no abastecimento de insumos às comunidades, como medicamentos e alimentos, uma vez que o transporte regular de cargas e passageiros por via fluvial ficaram restrito a excepcionalidades, como emergências/urgências médicas e serviços essenciais. É possível também que dados sobre casos novos e mortes por COVID-19 não tenham sido notificados pela dificuldade de comunicação entre os órgãos de saúde local e central.

\section{A PRESENÇA DA COVID-19 NO MODO DE VIDA DOS IDOSOS RIBEIRINHOS}

A interiorização da pandemia da COVID-19 é uma grande ameaça à saúde das populações ribeirinhas da Amazônia brasileira, que convive com diversas carências socioeconômicas e de saúde. Na vivência do idoso ribeirinho, destacam-se as condições de moradia deficitárias, que se caracterizam pelo número limitado de cômodos à quantidade de indivíduos por residência. As famílias vivem aglomeradas, com crianças, jovens, adultos e idosos dormindo no mesmo cômodo. O espaço do idoso é limitado, e diante de famílias disfuncionais, muitas vezes sofrem abandonos, negligências e várias formas de violência ${ }^{(6)}$.

Nas comunidades ribeirinhas, as informações chegam por meio da rádio, televisão, telefone ou meio impresso. Elas acontecem também por meio de rodas de conversa do final da tarde, nas pescarias, nas conversas da igreja, entre comadres e pelo Agente Comunitário de Saúde (ACS) durante a visita domiciliar. Mas, nem sempre os idosos compreendem as informações, seja pela maneira como ela é transmitida, pela diminuição da acuidade auditiva ou pela dificuldade de compreensão decorrente do analfabetismo de muitos idosos ribeirinhos. Assim, muitos idosos não conseguiram entender os aspectos mais importantes da COVID-19 e acabaram por se infectar e a morrer por causa da doença.

O distanciamento social é uma das orientações mais difíceis para ser seguida por idosos ribeirinhos que já têm seu ciclo de relacionamento social restrito a poucas pessoas. Para ele, o distanciamento social implica em deixar de ir à igreja, às vezes única atividade social; deixar de visitar parentes e comadres que moram próximo; deixar de receber pessoas que atracam nos portos e beiradas dos rios diante da residência; do encontro nos mercados para a venda e compra de produtos. $\mathrm{O}$ isolamento também produz nos idosos ribeirinhos, assim como para todos os idosos de qualquer lugar do planeta, sentimentos de carência, estado de ansiedade e depressão, tornando-o mais suscetível aos impactos provocados por uma pandemia que, para eles é completamente desconhecida e que provoca medo e alterações nas rotinas de sua vida ${ }^{(3,8)}$.

Nas comunidades ribeirinhas, a carência de saneamento básico e uso de água potável, tendem a potencializar a disseminação do vírus. Os ribeirinhos utilizam em grande parte, a água do rio para a higienização e preparo dos alimentos; para consumo; e higienização dos utensílios domésticos e do corpo ${ }^{(6)}$. Autores 
apontam para a transmissão fecal-oral do SARS-CoV-2 e sua presença no trato gastrointestinal de pacientes infectados, o que tem muitas implicações em áreas carentes de infraestrutura e saneamento básico. Por meio da contaminação da água, dos alimentos ou da transmissão mão/boca e da inadequada lavagem das mãos, os idosos podem se infectar ou mesmo a população estar despejando nos rios uma enorme quantidade de carga viral. Levando-se em consideração que a higienização das mãos é uma das mais importantes medidas preventivas diante da COVID-19, e que o idoso tem dificuldade de mobilidade para chegar até o rio, essa prática fica a desejar. Outras medidas protetivas recomendadas pelas autoridades sanitárias como o uso de máscaras e álcool a 70\%, são ações quase inexistentes devido à dificuldade de acesso aos itens ${ }^{(5)}$.

Deve-se considerar que o poder aquisitivo das famílias ribeirinhas é muito baixo, vivendo da pesca e agricultura, onde a prioridade é a produção de alimentos para subsistência e somente a venda do excedente gera alguma renda para a família ${ }^{(6)}$. Por outro lado, o idoso ribeirinho recebe auxílios financeiros como aposentadoria, benefícios do idoso, pensão do cônjuge falecido ou bolsa família, cujos dividendos são usados, em maior parte, na compra de alimentos e medicamentos para a família. Nesse caso, o risco de contágio se dá quando o idoso se desloca de sua comunidade à cidade para recebê-los, pois com o auxílio emergencial do governo, as pessoas que ficaram sem renda buscaram atendimento nos bancos e lotéricas, causando grandes aglomerações, tornando-se potencial fonte de transmissão do SARS-CoV-2.

Para sair da localidade onde mora, a via de transporte é o rio, por meio das embarcações, que acomodam os passageiros em poltronas ou redes, muito próximos, contribuindo para a transmissão do SARS-CoV- 2 . Embora tenham sido feitas orientações para uso de equipamentos de proteção individual, higienização das embarcações e distanciamento entre as pessoas, o cumprimento dessas medidas é negligenciado.

Nesse cenário, faz-se necessário uma avaliação crítica, a partir da própria logística da assistência prestada à saúde das comunidades ribeirinhas ${ }^{(4)}$. Nessas localidades, o acesso ao serviço de saúde é precário ou ausente, fazendo com que o idoso deixe de cuidar preventivamente de sua saúde. Atualmente as comunidades ribeirinhas da Amazônia Brasileira, contam com o apoio das equipes da ESF Ribeirinha e Fluvial, sendo composta principalmente pelo enfermeiro e ACS. Considerando a rapidez da disseminação da COVID-19, essas equipes não tiveram tempo suficiente para treinamentos relacionado aos cuidados específicos de prevenção e tratamento da doença junto à população, nem às especificidades pertinentes ao cuidado com o idoso vítima da COVID-19.

Embora vivam às margens dos rios, em lugares distantes e isolados, o distanciamento social estimulado por órgãos do governo e autoridades médicas sanitárias não assegura a proteção desses idosos ribeirinhos, no entanto, frente à pandemia que ora se enfrenta, a vulnerabilidade desse grupo etário e do precário sistema de saúde, o distanciamento social ainda é uma medida eficaz no combate à COVID-19. Ressalta-se, ainda, que para o enfermeiro atender idosos ribeirinhos nesse contexto, é importante que faça um planejamento da assistência à saúde, levando em consideração as peculiaridades da região e a cultura desse povo. A falta de planejamento dos serviços públicos para o enfrentamento, contribuiu de forma direta e indireta para o avanço da doença, vitimando pessoas e, em sua maioria, idosos ${ }^{(8)}$.

\section{CUIDADOS GERONTOLÓGICOS COM IDOSOS RIBEIRINHOS NO ENFRENTAMENTO DA COVID-19}

Um dos maiores desafios quando se discute cuidados relacionados à saúde de idosos ribeirinhos, está em contextualizar os aspectos sociais e culturais, visto que requer uma construção social capaz de absorver as suas reais necessidades de saúde. Além disso, as pessoas idosas possuem singularidades próprias, além da diversidade e complexidade do envelhecimento ${ }^{(3)}$. As populações ribeirinhas possuem um modo de viver peculiar, trabalhando e remanejando as possibilidades de existência em seus espaços, com formulação de estratégias que atendam sua necessidade e minimize a ausência dos serviços. Essas ações compartilhadas e de ajuda coletiva, apoiadas em conhecimentos tradicionais, ajudam no enfrentamento de doenças, escassez de assistência médica, equipamentos e serviços ${ }^{(6)}$. 
A assistência à saúde do povo ribeirinho é organizada e realizada a partir da Política Nacional de Atenção Básica, implantada no Brasil desde 2011 pelas Portarias MS/ GM n 2.488 e 2.490, voltadas para a operacionalização e financiamento das ações de saúde realizadas pelas Equipes de Saúde das Famílias Ribeirinhas (ESFR), juntamente com as equipes das Unidades Básicas de Saúde Fluviais (UBSF) presentes na região amazônica ${ }^{(9)}$.

Para o enfrentamento da pandemia, um dos primeiros pontos a considerar é o treinamento da equipe de saúde, no que diz respeito às especificidades da pandemia e aos cuidados gerontológicos, como estratégia de organização para a assistência, possibilitando a esses profissionais reconhecer-se no processo de trabalho e estabelecer/fortalecer vínculo com a pessoa idosa. O enfermeiro deverá estabelecer fluxos para triagem e acolhimento de casos suspeitos, fazer a notificação e orientações necessárias para a prevenção da COVID-19 ${ }^{(10)}$.

Os cuidados com a saúde de idosos ribeirinhos na pandemia por COVID-19 envolvem ainda: higiene frequente das mãos com qualquer tipo de sabão ou sabonete disponível na residência; dos calçados antes de adentrar ao domicílio; troca e lavagem de roupas utilizadas fora do domicílio; higiene corporal completa, incluindo cabelos; higienização com água e sabão ou álcool a 70\% de objetos de uso pessoal como bolsas, óculos, guarda-chuva; lavagem imediata das mãos ao manipular dinheiro, preferencialmente colocá-lo em um saco plástico e não mantê-lo em contato direto com o corpo; permanecer na comunidade em distanciamento social; evitar locais com aglomerações de pessoas como igrejas, mercearias, portos, embarcações, entre outros; usar máscaras caseiras; não cumprimentar tocando as pessoas; incluir a etiqueta respiratória e distanciamento ao espirrar ou em estado gripal; manter a situação vacinal atualizada e buscar atendimento imediato na presença de sintoma de COVID-19, como febre, tosse seca, dor de garganta, mialgia, cefaléia, alteração do olfato e paladar ${ }^{(10)}$.

A atuação gerontológica da equipe, em especial do enfermeiro, deve considerar o idoso de forma holística, atentando para as queixas, sinais e sintomas de doenças, aspectos físicos, condições sociais, econômicas, arranjos familiares, aspectos psicológicos, religiosos e culturais, estabelecendo condutas que assegurem sua recuperação. Em ambiente ribeirinho, é fundamental que os atendimentos sejam marcados e respeitados os horários, pois os deslocamentos demandam de horas de viagem, algumas vezes feitas em canoas e à remo e outras por longos caminhos no meio da floresta sob os perigos de cobras, onças e outros animais selvagens.

As políticas de saúde para os idosos ribeirinhos precisam ser implementadas de forma integrada com as demais políticas públicas, com objetivo de alcançar a universalidade da assistência e a garantia de direitos à saúde, que perpassam pelo acesso aos serviços de saúde, saneamento básico, educação, habitação, alimentação, água potável e outros considerados essenciais. Para que isso aconteça, deve-se priorizar a regularidade e continuidade da assistência; comprometimento dos gestores e de toda equipe no sentido de prover condições para efetuar a assistência; investimentos na formação profissional; e valorização das pessoas idosas no processo de aprendizado para o autocuidado, levando em consideração todo seu contexto biopsicossocial, cultural, espiritual, ambiental e geográfico.

\section{CONTRIBUIÇÃO PARA A ENFERMAGEM}

Sendo o enfermeiro (a) o principal agente da assistência à saúde para essas populações, sua atuação na prevenção da COVID-19 é de fundamental importância, visto que em muitas comunidades ribeirinhas, o acesso à saúde e informações são insuficientes, seja por fatores geográficos de distanciamento ou por falta de atuação e ingerência de instituições governamentais. Pretende-se contribuir para reflexão sobre a pouca visibilidade ou ausência do cuidado de enfermagem gerontológica à população idosa ribeirinha, necessitando de incentivos para formações nessa área; valorização do conhecimento e práticas populares em saúde desenvolvida no contexto ribeirinho da Amazônia brasileira, onde se deve valorizar saberes, crenças e culturas e as características de cada região e, por fim, destacar a necessidade de investimento na formação para os cuidados na atenção primária à saúde para atuação em unidade de saúde ribeirinhas e fluviais para a especificidade do atendimento ao idoso no contexto ribeirinho. 


\section{CONSIDERAÇÕES FINAIS}

No dimensionamento territorial do Brasil, encontram-se populações rurais vivendo às margens dos rios que entrecortam a imensa floresta Amazônica, conhecidas como comunidades ribeirinhas, que diante de suas características geográficas, culturais e sociais, enfrentam inúmeros desafios para obter saúde ou preservá-la, passando pelas precárias condições de saneamento básico, longas distâncias nos deslocamentos para atendimento, ausência de assistência médica e de enfermagem especializada e dificuldade de transporte e comunicação. Nesse contexto, estão grupos de maior vulnerabilidade como as pessoas idosas que, diante da Pandemia da COVID-19, precisou se adaptar ao isolamento social e adquirir novos hábitos de cuidados completamente desconhecidos como o uso de máscara e álcool em gel.

O enfrentamento da pandemia por COVID-19 por idosos ribeirinhos que vivem na Amazônia brasileira requer planejamento, estratégias diferenciadas, equipes preparadas e incentivos nas ações por parte do sistema de saúde. As ações previstas pelo Sistema Único de Saúde (SUS) não chegam para todos, portanto muitos idosos são negligenciados ou não recebem assistência adequada à saúde. A Enfermagem ribeirinha e fluvial enfrenta inúmeros desafios, desde o deslocamento via canoas e pequenos motores, a falta de insumo e apoio. No que diz respeito aos cuidados gerontológicos, faz-se necessário treinamentos e formação das equipes, para prestar assistência qualificada e diferenciada de acordo com o modo de vida ribeirinho. Recomenda-se cursos de formação nesta área de forma remota, considerando a dificuldade de deslocamento do profissional de saúde e as necessidades das pessoas idosas que vivem nas comunidades ribeirinhas.

\section{AGRADECIMENTO}

\section{Ao Departamento Científico de Enfermagem Gerontológica da ABEn Nacional.}

\section{REFERÊNCIAS}

1. Shi H, Han X, Jiang N, Cao Y et al. Radiological findings from 81 patients with COVID-19 pneumonia in Wuhan, China: a descriptive study. The Lancet Infectious Diseases [Internet]. 2020 [cited 2020 Jun 12];20(4). Available from: https://www. thelancet.com/action/showPdf?pii=S1473-3099\%2820\%2930086-4

2. Brasil. Ministério da Saúde. Secretaria de Vigilância em Saúde. Boletim Epidemiológico Especial COE-COVID 19. Brasília, DF: Ministério da Saúde, 2020. [cited 2020 Jun 13]. Available from: https://static.poder360.com.br/2020/06/brasil-covidboletim.pdf

3. Hammerschmidt KSA, Santana RF. Health of the older adults in times of the COVID-19 pandemic. Cogitare enferm. [Internet]. 2020 [cited 2020 Jun 14]; 25: e72849. [cited 2020 Jun 12]https://revistas.ufpr.br/cogitare/article/view/72849/pdf_en

4. Gonçalves RM, Domingos IM. População ribeirinha no Amazonas e a desigualdade no acesso à saúde. RECHTD [Internet]. 2019. [cited 2020 Jun 12]; 11(1):99-108. Available from: http://www.revistas.unisinos.br/index.php/RECHTD/article/ viewFile/rechtd.2019.111.06/60747117

5. Nascimento RG, Cardoso OR, Pinto DS, Magalhães CMC. Fragilidade de idosos ribeirinhos amazônicos: das trajetórias metodológicas aos desafios em saúde pública. Revista Saúde e Pesquisa, Maringá (PR) [Internet]. 2019. [cited 2020 Jun 14]; 12(2): 367-375. Available from: https://periodicos.unicesumar.edu.br/index.php/saudpesq/article/view/7196/3527

6. Gama ASM, Fernandes TG, Parente RCP, Secoli SR. Inquérito de saúde em comunidades ribeirinhas do Amazonas, Brasil. Cad. Saúde Pública. [Internet]. 2018. [cited 2020 Jun 16];34(2):e00002817. Available from: https://www.scielo.br/pdf/csp/ v34n2/1678-4464-csp-34-02-e00002817.pdf

7. Instituto Brasileiro de Geografia e Estatística (IBGE). Para conter Covid-19, IBGE antecipa dados de acesso da população a serviços de saúde. Agência IBGE. Editoria: Séries Especiais. [Internet]. 2020 [cited 2020 Jun 14]; Available from: https://agenciadenoticias.ibge.gov.br/agencia-noticias/2012-agencia-de-noticias/ noticias/27338-para-conter-covid-19-ibge-antecipa-dados-de-acesso-da-populacao-a-servicos-de-saude 
8. Mendonça FD, Rocha SS, Pinheiro DLP, Oliveira SV. Região Norte do Brasil e a pandemia de COVID-19: análise socioeconômica e epidemiológica. Journal Health NPEPS. [Internet]. 2020. . [cited 2020 Jun 12];5(1):20-37. Available from: https://periodicos.unemat.br/index.php/jhnpeps /article/view/4535

9. Brasil. Ministério da Saúde. Secretaria de Atenção à Saúde. Departamento de Atenção Básica. Passo a passo das ações do Departamento de Atenção Básica. Brasília, DF: Ministério da Saúde, 2012 [cited 2020 Jun 17]. Available from: http://189.28.128.100/dab/docs/publicacoes/geral/passo_passo_acoes_sb.pdf

10. Souza CRS, Reis DA; Castro FF, Carreira L, Nascimento V. Prevenção da covid-19 na população idosa indígena. In: Enfermagem gerontológica no cuidado do idoso em tempos da COVID 19. Associação Brasileira de Enfermagem. Brasília, DF: ABen/DCEG. [Internet]. 2020. 2012 [cited 2020 Jun 18].74 p. (Série enfermagem e pandemias). Available from: http:// www.abennacional.org.br/site/wp-content/uploads/2020/05/E-BOOK-GERONTO.pdf 